\title{
TURBIDITY METER FOR DETERMINATION OF WATER TURBIDITY LEVEL BASED ON SEMICONDUCTOR COMPOUND
}

\author{
J.B. SAPAEV ${ }^{1}$, A. ARIFJANOV ${ }^{1}$, B. SAPAEV ${ }^{2}$, B.M.KAMANOV ${ }^{1}$, L. SAMIEV ${ }^{1}$, SH.H. ISMOILOV ${ }^{3}$ \\ ${ }^{I}$ Tashkent Institute of Irrigation and Agricultural Mechanization Engineers, Kori Niyoziy St, Tashkent, Uzbekistan \\ ${ }^{2}$ Tashkent State Agrarian University
}

${ }^{3}$ Urgench branch of the Tashkent University of Information Technologies named after Muhammad al-Khwarizmi

\begin{abstract}
The paper includes the data about reclamation state of the water, characteristic of the degree of water pollution, the work process of the device for determination degree of pollution in the OD's in the territory of the Republic of Uzbekistan. Its structural graph, the place occupied in determining the amount of water pollutions are shown and its distinction and advantages over other devices are analyzed. Physical and chemical properties of the electronic graph of the assembled device is analyzed. The analysis of scientific novelty of modern value, technical and economic performance of the device is shown.
\end{abstract}

KEYWORDS: Land Reclamation Condition of Water, the Degree of Soil Pollution, the Instrument to Determine the Degrees of Water Pollution, Electronic Graph, the Differences, Advantages

Received: Jun 08, 2020; Accepted: Jun 28, 2020; Published: Sep 18, 2020; Paper Id.: IJMPERDJUN20201333

\section{INTRODUCTION}

Does everyone understand that water is a great gift of nature? Unfortunately, getting a positive answer to this question from all people is not possible, otherwise our attitude to water today would not be so terribly bad. Perhaps, if any person had complete information about water, the ecological indicators of our life would not be so disturbed [1].

Natural waters can be various in its content, in terms of quality and is the number of a and include the following types: salt water - water in the seas, oceans, fresh water - water from rivers and springs of rivers, underground water in wells, water from snow and rain, mineral waters, in some cases even an example of hot groundwater can be cited.

But at the same time, it is important to know that even water in the same river or river does not necessarily have the same composition and properties in different places along the entire length of the river [2]. That is why the ancient Greek scientist and philosopher Heraclitus in the 5th century BC stated that it is not possible to submerge twice in water of the same composition in a river, because every time a person immerses in water, he bathes in water of a new composition and quality in the same place for swimming in the river. Due to the increasing anthropogenic factor in nature, that is, the activity of many industrial enterprises, agricultural crops, municipal services, the medium evaporates from various wastes, contaminated run-off, the problem of clean water is the most urgent problem today [3]. 


\section{METHODS}

Water quality is assessed not only by transparency, but also by the degree of turbidity. When assessing the quality of water turbidity, the nature of the turbidity and the type of cages are described using the following terms: more or less coarse gray, brown, black, cloudy mucus, sand particles, and some other particles. Turbidity of water to a depth of $20-30 \mathrm{~cm}$ is considered to be weaker. The transparency of water at a depth of $10-20 \mathrm{~cm}$ is muddy, and the transparency of water above $10 \mathrm{~cm}$ is very turbid [4]. We know that many of our districts and villages, located at the foot of the mountain, use flood waters in the early spring. Determining the turbidity level of water coming from the mountains causes some problems. This is due to the fact that high levels of turbidity in the water adversely affect the development of crops. The water is tested in a laboratory to determine how cloudy it is. The turbidity of the water is determined by comparing the test sample with a standard solution. A standard solution is prepared by adding a suspension of $\mathrm{SiO}_{2}$ to distilled water. The degree of haze is measured in $\mathrm{mg} / \mathrm{l}$. The turbidity of river water is higher than that of underground water. The size of the mud depends on the suspended particles in these waters, in other words, mud, sand, plankton, plant debris. The turbidity of river water can be several mg per liter of water. The turbidity of drinking water should not exceed $2 \mathrm{mg} / 1$. The amount of insoluble and colloidal particles in water can be determined by the transparency index. The transparency index is measured on a glass cylinder 30-50 cm high. In this case, the height of the water layer in centimeters at which the text of a certain font is visible is called the purity of the water font. The filtration method is used to detect suspended particles in water. The water is filtered and the filter is dried at $105^{\circ} \mathrm{C}$. The difference in filter mass, measured before and after filtration, indicates the amount of suspended particles in the water [5]. Turbidity is an optical device designed to study the concentration of substances in solutions. The application process is usually based on the ability of colored solutions to refract light passing through them, depending on the concentration of the dye. With the help of a turbidity meter, measurements are carried out on a part of the spectrum in monochromatic light, which is best absorbed by the substance under study (accordingly, much weaker than other components of the solution).

\section{RESULTS AND DISCUSSIONS}

Device features of sets of individual optical filters with narrow spectral band that allows to study the concentration of various components in the same solution. As can be seen from Figure 1, a photocell is the main component of the turbidity meter. The higher the photocell sensitivity is, the higher the accuracy of the turbidity meter will be. For this purpose, we used pSi-nCdS, nSi-pCdTe, pSi-pCdTe-nCdS, pSi-nCdO, pSi-pCdTe-nCdO cells as photocells.

Photosensitive pSi- n CdS, nSi-pCdTe, pCdTe-pSi-nCdS, pSi-nCdO, pCdTe-pSi-nCdOstructures were created by sputtering CdS powders and CdTe (in quasi-closed system in a vacuum of $10^{-5}$ torr) on a silicon plate surface $\mathrm{p}$, n-type with a resistivity $\rho \approx 10 \Omega \cdot \mathrm{cm}$ and a thickness of $300 \mu \mathrm{m}$, as in [6 -7 ].The Si substrates were prepared (lapped and polished) under plant conditions inaccordance with a Russian Federation State Standard. At the same time, contamination on the surface of the silicon wafers due to prolonged storage was removed by an alkaline etchant: aqueous $5 \% \mathrm{KOH}$ solution.

The etching time was $8-10 \mathrm{~min}$. Next, given that $\mathrm{KOH}$ is difficult to remove from the surface, the substrates were thoroughly rinsed by a displacement method [6]in two steps. First, the substrates were rinsed in running distilled water for 8-10 min. After that, they were rinsed in deionized water ( 20 M $\Omega$ ) for 3-5 min.Next, the substrates were placed in an infrared drying oven for 15-20 min. 
Most (70-80\%) of the samples produced on the substrates cleaned as described above were similar in properties (photosensitivity and shape of current-voltage $(I-V)$ curves). For 20-30\% of the samples, deviations of their main parameters were as large as $50-80 \%$. Films $C d O$ was and prepared s by magnetron -ion sputtering of cadmium atoms on the surface of films of cadmium telluride. The upper contact, from the side of which the illumination is carried out, was made of indium, deposited in a vacuum of $\sim 10^{-5}$ torr in the form of the letter "P".

The source temperature $(\mathrm{CdS}$ and $\mathrm{CdTe}) \mathrm{T}_{\text {source }} \approx 800-850^{\circ} \mathrm{C}$, and on the substrate $(\mathrm{pSi}$ ) it was maintained within the range of $\approx 250-270^{\circ} \mathrm{C}$.

Further with spectral dependence photosensitive element structures measured at 3MP-3 monochromator at room temperature $\mathrm{T}=300 \mathrm{~K}$. The radiation source was a DKSSh-1000 xenon lamp operating in the minimum allowable power mode. The lamp provided a luminous flux of 53,000 lm and a brightness of up to $120 \mathrm{MCd} / \mathrm{m}^{2}$ in the center of the light spot. The lamp radiation is calibrated in absolute units using an RTE-9 thermoelement with a quartz window. The DKSSh1000 lamp has a continuous spectrum in the ultraviolet and visible regions [7] .

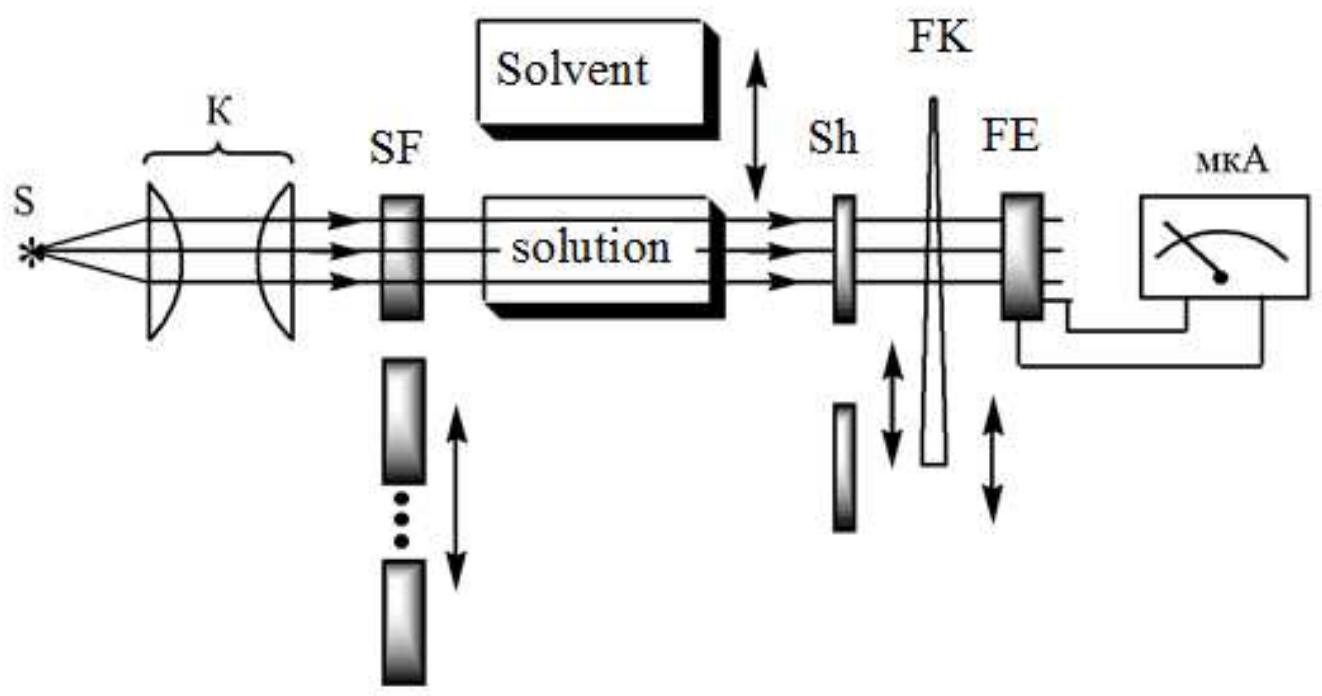

Figure 1: Turbidity meter electronic circuit

In Figure $2 \mathrm{a}, \mathrm{b}$ shows the spectral distributions of photosensitivity. Analysis of the curve of the spectral distribution of photosensitivity in the forward direction of the current shows (see Figure $2 \mathrm{a}, \mathrm{b}$ ).

The $p \mathrm{Si}-p \mathrm{CdSh}$ terostructures produced in this study were characterized by current-voltage $(I-V)$ measurements. To this end, electrical contacts were made by vacuum deposition of indium: continuous contacts to the Si substrate and point contacts with an area of $\sim 1 \mathrm{~mm}^{2}$ to the $\mathrm{nCdS}$ layer. As seen in Fig. 2 a, the $I-V$ curve thus obtained has a typical form corresponding to a diode structure. 


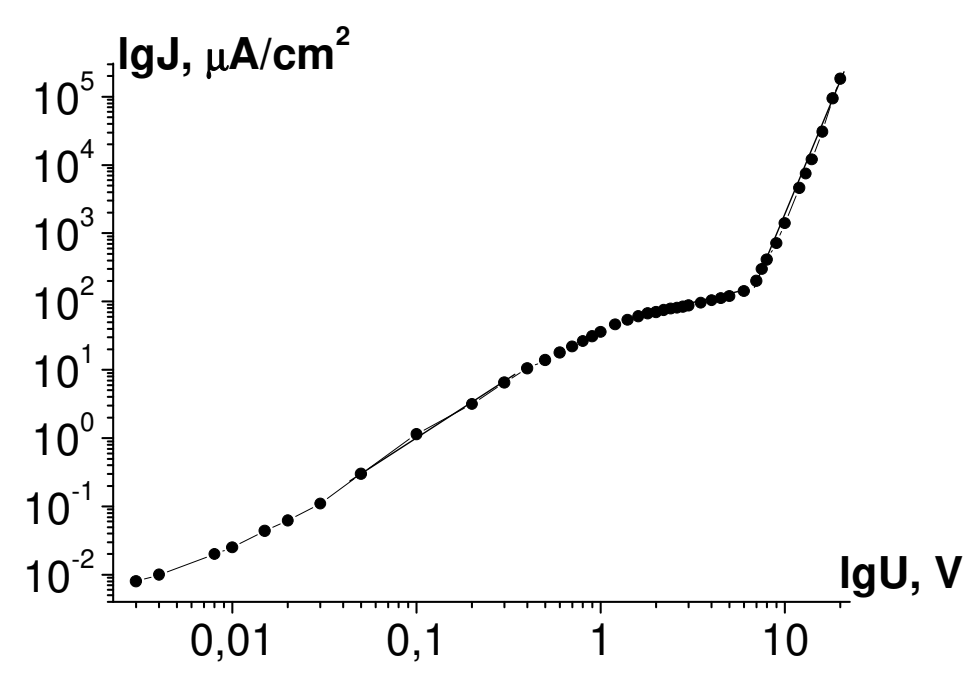

Figure 2a: I-V curve of the pSi-pCdS hetero structure [6]

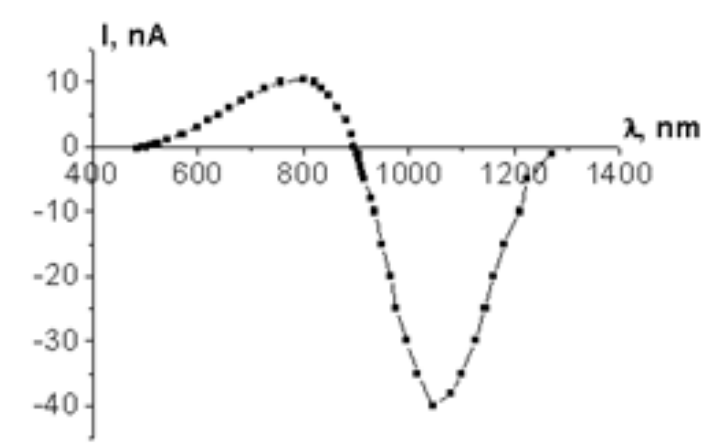

Figure 2b: Spectral dependences of photosensitivity of pSi - pCdTe - nCdS [7]

Spectral dependences of photosensitivity of b)pSi - pCdTe - nCdS - M structures: that they have a spectral range of $\lambda=489-1300 \mathrm{~nm}$.

From the spectral dependences contact was determined spectral photosensitivity of these structures thats are equal to $1,8 \mathrm{~A} / \mathrm{W}$ for $\mathrm{pSi}$ - $\mathrm{pCdTe}-\mathrm{nCdS}$ structure, for - $\mathrm{nCdS}$ - $\mathrm{pSi}$ - structure are equal to $\sim 2.1 \mathrm{~A} / \mathrm{W}, 1,6 \mathrm{~A} / \mathrm{W} \mathrm{pSi}-\mathrm{nCdO}$ and $1,4 \mathrm{~A} / \mathrm{W}$ for pSi-pCdTe-nCdO structures $\mathrm{s}$. From these data it is clear that highest spectral photosensitivity is obtainedfor the - nCdS - pSi - structure. This shows that the accuracy of determining the turbidity of water using a turbidity is obtained on the basis of - $\mathrm{nCdS}-\mathrm{pSi}$ - structure.

\section{CONCLUSIONS}

- Studies have shown that indeed, structures s very sensitive to low light levels and they have tons higher values of spectral sensitivity and in private, and in the Prima waist absorption areas of light and turbidimeters water, manufacturing of e on the basis of these elements to measure that turbidity is more accurate. 
- $\quad$ It has been proposed to measure the turbidity of water as a percentage (\%).

- Determination of the degree of turbidity of flowing and stagnant waters in 5 seconds has been achieved.

- The main differences from similar turbidity meters given in the literature are that in our turbidity meters, the speed of working time, low cost, compactness, high measurement accuracy (error $0.5 \%$ ) are achieved.

\section{Technical characteristics of the turbidity meter}

\begin{tabular}{|l|c|}
\hline \multicolumn{1}{|c|}{ Technical Characteristics } & FEK \\
\hline Spectralnyrange, nm & $400-1300$ \\
\hline $\begin{array}{l}\text { D Range and Measurements: } \\
\text {-SKNP, } \\
\text { - optical density }\end{array}$ & $0.1-100$ \\
\hline Concentrationmeasuringrange & $0-3$ \\
\hline Measurement accuracy (\%) & $0.001-999.9$ \\
\hline $\begin{array}{l}\text { Wave length measurement error } \\
\text { (nm) }\end{array}$ & 0.5 \\
\hline Working trench length (mm) & 3 \\
\hline Source of electricity & $1,3,5,10,20,30,50,100$ \\
& $4.5 \mathrm{~V}$, frequency 500.5 \\
\hline Radiation source & Hz \\
\hline Power consumption & Halogenlichiro K \\
\hline Size (cm) & $1 \mathrm{~W} /$ minutes \\
\hline Weight (kg) & $50 \times 5 \times 5$ \\
\hline
\end{tabular}

\section{REFERENCES}

1. Churkin A.V., Uarova R.M., Shashlov A.B. Basics of lighting engineering. Textbook - M .: MGUP, 2002. Electronic version.

2. Fundamentals of lighting, part 1. Laboratory work. Uralova R.M., Churkin A.V., Shashlov A.B. - M .: MGUP, 2008

3. Fundamentals of colorimetry. Laboratory works. Churkin A.V., Shashlov A.B. - M .: MGUP, 2008.

4. Fundamentals of lighting, part 1. and part 2. Examinations and guidelines for the cycle of general professional disciplines in the specialty 281400. R.M. Uarova, A.B. Shashlov, A.V. Churkin. - M .: MGUP, 1999, p. 110-171.

5. Fundamentals of lighting technology Tasks for practical training. Shashlov A.B., Uarova R.M., Sterlikova A.V., Churkin A.V. - M.: MGUP, "Book World", 2004.

6. S.A. Mirsagatov, I.B. Sapaev. Photoelectric and electrical properties of a reverse-biased p-Si $/ n^{-C d S} / n^{+}-$ CdSheterostructure//Inorganic Materials 50 (5). 437-442. (2014).

7. S.A. Mirsagatov, I.B. Sapaev, S.R. Valieva, D. Babajanov. Electrophysical and Photoelectric Properties of Injection Photodiode Based on pSi-nCdS-In Structure and Influence of Ultrasonic Irradiation on them//Journal of Nanoelectronics and Optoelectronics 9 (6), 834-843. (2014). 

